\title{
Announcement
}

\section{Competition Paper}

The journal invites articles on Thoracic, Cardiac and Vascular Surgery, written and authored by a post-graduate trainee (M.ch.). The article should be original, not awaiting consideration/ publication elsewhere and must conform to the requirements of the IJTCVS. There may be other authors but first author must be registered for M.Ch. in a recognized institution and must submit a certificate from Head of the department. The article must be full length. No brief reports, case reports, how to do it, etc will be accepted. The article will be reviewed and if recommended for publication will then be given to a panel of judges. The prize winning author will receive a certificate and Rs. 5000/- at the next conference of the IACTS. The second and third prize winners will receive certificates and Rs. 2000/- and Rs. 1000/- respectively. All articles will become property for the IJTCVS and be published in forthcoming issues. The decision of the judges will be final and no correspondence will be entertained.

Articles must reach the editorial office latest by October 30th, 2002 and must be superscribed Competition Paper. It will be considered only if accompanied by a certificate from the HOD and a copyright release statement as mentioned in instructions to authors. 